\title{
BASE ISOLATED BUILDINGS WITH CURVED SURFACE SLIDERS INCLUDING DISPLACEMENT RESTRAINTS
}

\author{
FELICE C. PONZO ${ }^{1}$, ANTONIO DI CESARE ${ }^{1 *}$, ALESSIO TELESCA ${ }^{1}$ AND \\ DOMENICO NIGRO ${ }^{1}$
}

\author{
1 School of Engineering, University of Basilicata \\ Viale dell' Ateneo Lucano, 10 - 85100 Potenza, Italy \\ felice.ponzo@unibas.it; antonio.dicesare@unibas.it; alessio.telesca@unibas.it; \\ domenico.nigro@unibas.it
}

Key words: Base isolated structures, Curved Surface Sliders, Displacement Restraints, NonLinear Static Analysis.

Summary. Recent researches on seismic isolated structures are focused on the behaviour of isolation devices when extreme loading conditions are applied, with displacement demands higher than the design value [1]. Generally, the design displacement is considered as the collapse limit and no further capacity is taken into account [2]. This study investigates the effects of the presence of displacement restraints on the response of seismically isolated buildings based on Double Curved Concave Surface Sliders (DCCSS) for displacements larger than the design values. Two residential buildings case studies are considered with moment resistant steel or reinforced concrete frames both isolated with DCCSS [3] [4]. The isolated structures satisfy prescriptions of the current Italian seismic code considering the same seismic actions for the site of L'Aquila. Pushover analyses are carried out in order to estimate the engineering demand parameter (Superstructure Global Drift) limit values used for the definition of the superstructure failure condition. The effects of the impact of the isolation systems against retaining elements on the seismic response of isolated structures are highlighted. The results of multi-stripe analyses using twenty ground motions at ten different seismic intensities [5] are compared.

\section{INTRODUCTION}

Base isolation is one of the most widespread techniques currently used for the seismic protection of buildings and their equipment. Isolation devices are designed to carry the Maximum Considered Earthquake (MCE) design displacement so that the superstructure stays in the elastic range for Design Basis Earthquake (DBE) seismic intensities.

Combining two sliding concave surfaces the result is a Double Concave Curved Surface Slider (DCCSS) bearing, which produces two independent pendulum response mechanisms. When upper and lower pads are characterized by the same radius of curvature and friction coefficient, sliding occurs simultaneously on both surfaces until extreme conditions such as uplift and/or contact with a displacement restrainer are reached. The effectiveness of curved surface sliders isolation systems has been proven by experimental campaigns and analytical 
studies investigating on main aspects such as the influence of vertical load, sliding velocity and frictional heating on the friction coefficient variation and on the re-centring capability of the system. These devices have been studied in many different applications on new and existing buildings, other structural elements and bridges, examples are given in [6] [7] [8].

Recent studies consider that the isolation system failure may occur when the actual isolator displacement capacity $d_{C}$ is reached, see Figure $1 \mathrm{~b}$ ), such as when earthquakes stronger than the design one occur. The use of displacement restraints such as restraining rings or moat walls is admitted by American standard. On the contrary, the European Standard does not allow the presence of restraining element and only approves the use of structural joints separating the superstructure from the surrounding constructions, in order to safely accommodate the seismic movement. Retaining elements impact has not been widely observed and studied in the past, except for the studies of Masroor and Mosqueda in 2012 [9] and Bao and Becker in 2017 [10]. In [9] an impact element considering moat wall flexibility is proposed based on theoretical observations and experimental simulations to better understand the consequences on the superstructure of the impact. In [10] an extended experimental campaign to investigate the extreme behaviour of double pendulum sliding bearings under strong ground motions was conducted, considering scaled bearings with four different types of restraining elements representing typical devices found in Europe, Japan, and the United States.

Other retaining elements such as Shape Memory Alloy (SMA) devices combined with DCCSS are studied by De Domenico, Gandelli and Quaglini in 2020 [11] [12]. Parametric studies on this combined system reveal how SMA devices are suitable to limit the maximum displacement under hig high re-centring capabili In this study, the effection base-isolated buildings of stiffness is defined to represent the generic stiffnes elements. Two models of DCCSS-isolated moment resistant frames, a Steel and a Reinforced

\section{MODELIING OF DCCSS BEARINGS WITH DISPLACEMIENT RESTRAIITS}

Nonlinear numerical models including both inelastic superstructures and isolation devices are adopted by using OpenSEES [13].

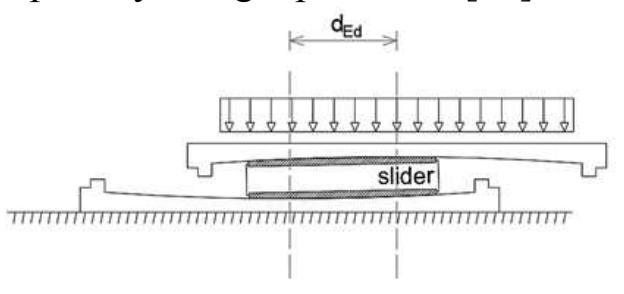

a)

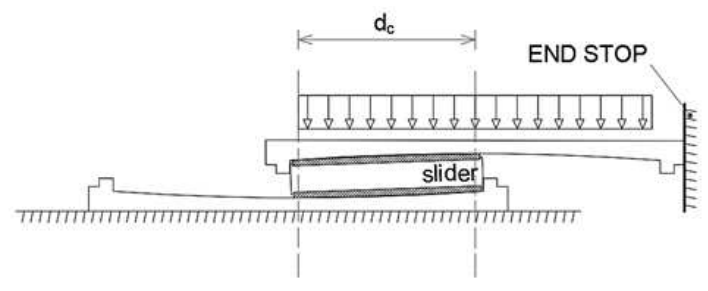

b)

Figure 1: DCCSS isolators sliding at: a) design displacement; b) maximum displacement.

In particular, specific nonlinear models have been developed for the isolation devices to correctly predict the response of the isolated building when motion is interrupted by rigid or flexible displacement restrainers. 
The Single FP Bearing element implemented in OpenSEES has been selected to describe the cyclic behaviour of the basic DCCSS isolator [4]. The friction coefficient is modelled accounting for its dependency on sliding velocity, while the effects of temperature and contact pressure are neglected [14].

Displacement restraints consisting of a zero-length gap element with either infinitely rigid or flexible behaviour were added to the basic model of each isolator from $\mathrm{j}$-node to s-node of Figure 2 a). The model is not dissipative during the impact between the retaining element and the sliding pad or the base slab. The flexible restraint was modelled using a gap stiffness $\left(K_{g a p}\right)$ proportional to the superstructure one $\left(K_{s t r}\right)$ and with unlimited yielding strength. The gap amplitude equals the bearings displacement capacity $d_{C}$, as in Figure $2 \mathrm{~b}$ ) were the forcedisplacement behaviour of the modified DCCSS model is also shown.

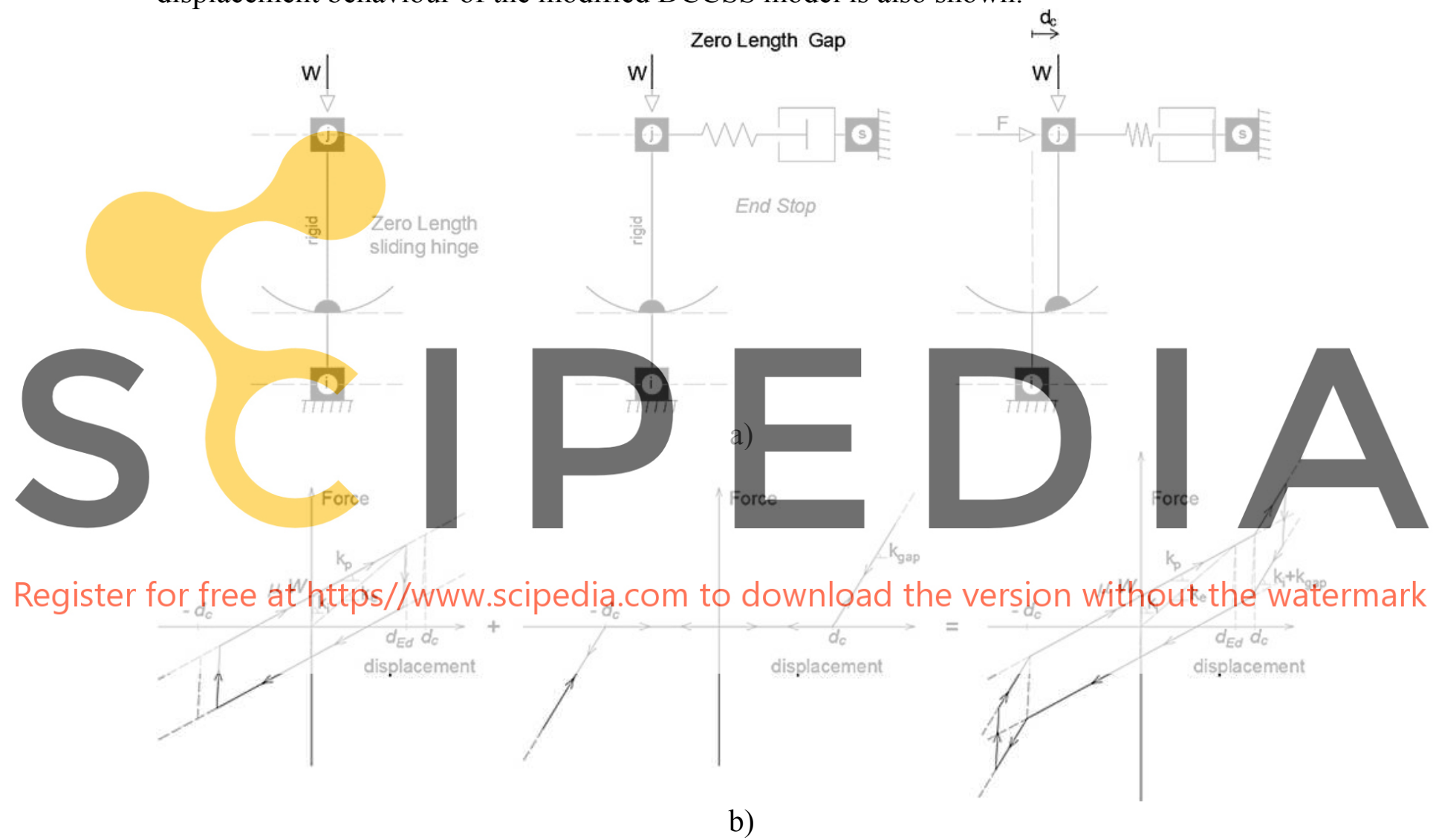

Figure 2: Spring representation of the SingleFPBearing OpenSEES element (a), force-displacement relationship for the element (b).

\section{LAYOUT AND DESIGN OF BI STRUCTURES}

This study is based on two residential buildings. One is a 6-story steel 2D moment resistant frame, considered as a case study in Kitayama and Constantinou 2019 [15], in Ponzo et al. 2020 [16] and in Di Cesare et al. [17] designed according to the Italian seismic code NTC18 [18]. The second is the prototype of a 5-story reinforced concrete (RC) moment resistant 2D frame considered as a case study in Mazza and Vulcano 2012 [19], designed according to Eurocode 8 [20] and satisfying prescriptions imposed by NTC08 [15]. Both structures, classified as 
ordinary with an importance factor $\mathrm{c}_{\mathrm{u}}=1$, are designed for a location in the city of L'Aquila, central Italy, and medium soil class $\mathrm{C}$.

Beam and Column elements have been modelled with a lumped plasticity approach for the superstructure, whereas elastic beams have been used for the base floor grid above the isolation system. Second order effects have not been considered. For both structures, the modified IbarraMedina-Krawinkler deterioration model (IMK) [21] has been used for plastic hinges modelling. For the Steel Frame, member capacities have been calculated using the expected yield strength of the steel material $275 \mathrm{MPa}$ and panel zones have been modelled with rigid-elastic elements by using a two-nodes link element with length equal to half of the section depth. For the RC Frame model, plastic hinges in the joints have been represented using zero-length TwoNodeLink elements.

\subsection{Moment resistant frame case studies}

The Steel Moment Resistant Bare Frame (SMF) has been designed for gravity loads only respecting minimum criteria required by Eurocode and considering low ductility class for structural details. Seismic weights $W_{i}$ and masses $M_{i}$ of each floor, see Figure 3 a), are listed in Table 1. The total seismic weight $W$ of the isolated frame is about $5000 \mathrm{kN}$ and the vertical load on the internal isolators is $N_{S d}=1680 \mathrm{kN}$

The Reinforced Concrete moment resistant test structure has been designed according to Eurocode 8 (EC8) [20], assuming the gravity loads combined with either the horizontal seismic

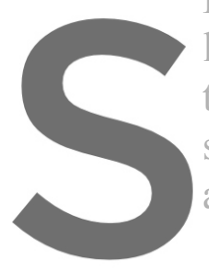
loads or the horizontal the superstructure on the see Figure 3 b), are about $1320 \mathrm{kN}$ and the
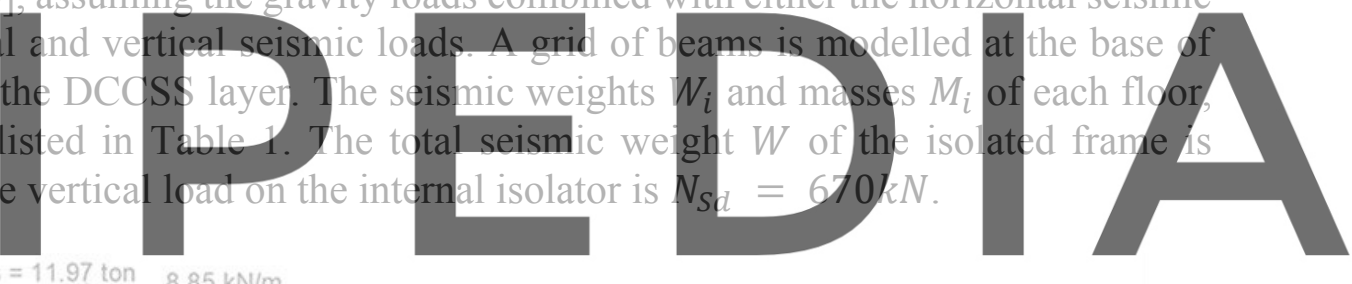

Register for free atshttpshawwW:SGipedia.Gom to download the version without the watermark

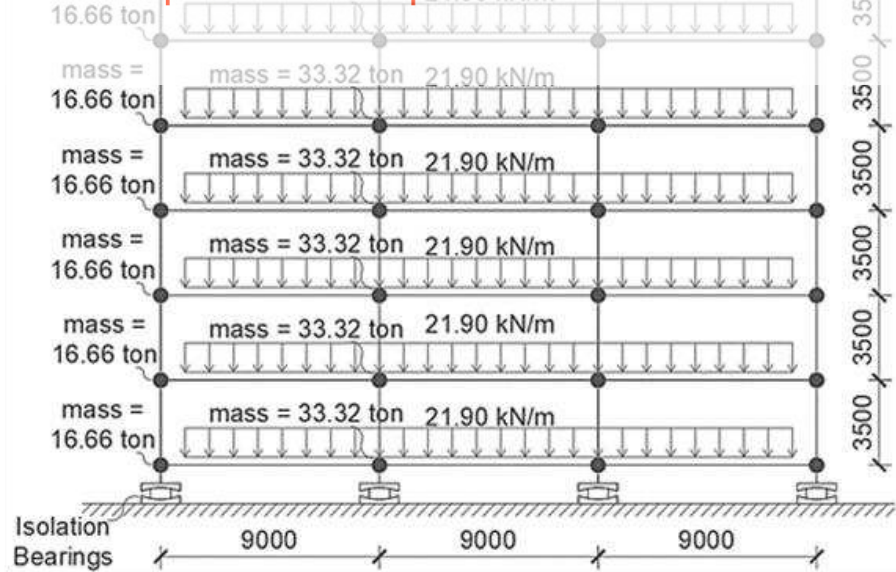

a)

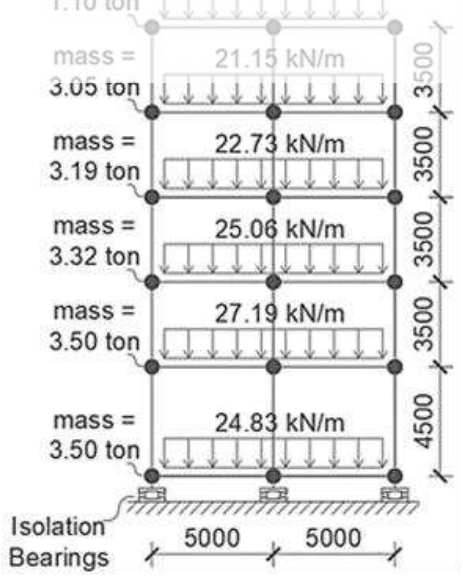

b)

Figure 3: Representation of gravity loads in the isolated configuration for the Steel (a) and the Reinforced Concrete (b) moment resistant frame case studies. 
Table 1: Gravity and seismic loads and masses of the moment resistant steel frame.

\begin{tabular}{|c|c|c|c|c|c|c|c|c|}
\hline Masses $\boldsymbol{M}_{\boldsymbol{i}}[\boldsymbol{I t o n}]$ & Base & $\mathbf{1}^{\text {st }} \mathbf{f l o o r}$ & $\mathbf{2}^{\text {nd }} \mathbf{f l o o r}$ & $\mathbf{3}^{\text {rd }} \mathbf{f l o o r}$ & $\mathbf{4}^{\text {th }}$ floor & $\mathbf{5}^{\text {th }} \mathbf{f l o o r}$ & $\mathbf{6}^{\text {th }} \mathbf{f l o o r}$ & $\boldsymbol{T o t a l}$ \\
\hline Steel Frame & 99 & 100 & 100 & 100 & 100 & 100 & 36 & 634.5 \\
\hline RC Frame & 25.3 & 27.7 & 25.5 & 23.2 & 21.6 & 11.2 & - & 135 \\
\hline
\end{tabular}

The superstructure stiffness, in the not-isolated configuration, has been computed using the information gained by linear-dynamic analyses about the mass participation factors in the first vibration mode. The single structural element stiffness has been considered in a "shear-type" configuration, and, for floor stiffness, all structural elements were considered in parallel, the first vibration period and the superstructure stiffness are reported in Table 2

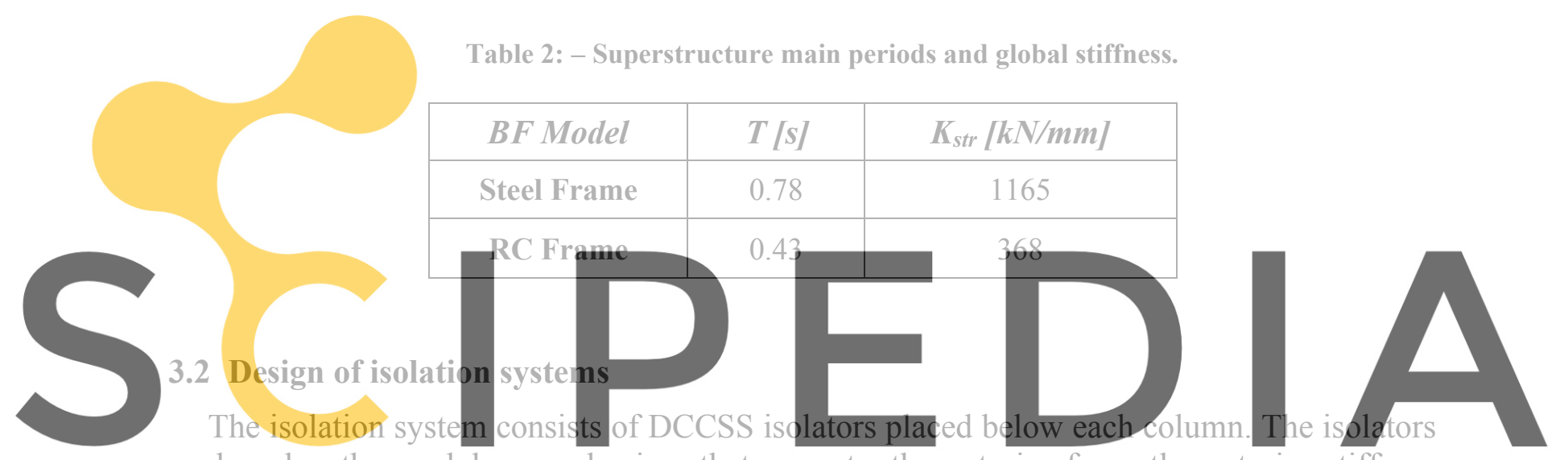
are based on the pendulum mechanism, that generates the restoring force, the restoring stiffness

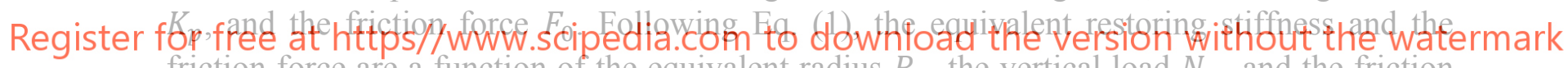
friction force are a function of the equivalent radius $R_{e}$, the vertical load $N_{S d}$ and the friction coefficient $\mu$.

$$
F_{0}=\mu N_{s d} ; \quad k_{p}=\frac{N_{s d}}{R_{e}}
$$

The isolated structure effective period $T_{e}$ is independent of the superstructure mass $M$, as it only depends on the equivalent radius $R_{e}$ and the design displacement $d_{E d}$ of the isolation system which is obtained considering the MCE reduced by the effective damping $\xi_{\text {eff }}$, see Eq. (2) and Figure 4. The pre-sliding stage of motion has been modelled with a quasi-rigid behaviour considering a high initial stiffness $K_{i}$. Isolation systems have been designed using the MCE $\xi_{\text {eff }}$ damped spectrum according to the Italian seismic code [18] for a location in the city of L'Aquila, central Italy, and medium soil class C as shown in Figure 4.

$$
K_{e}=N_{S d} \cdot\left(\frac{1}{R_{e}}+\frac{\mu}{d_{E d}}\right) ; \quad \xi_{e f f}=\frac{2}{\pi} \cdot \frac{1}{\left(\frac{d_{E d}}{\mu \cdot R_{e}}\right)+1} ; \quad T_{e}=2 \pi \sqrt{\frac{1}{g \cdot\left(\frac{1}{R_{e}}+\frac{\mu}{d_{E d}}\right)}}
$$

Considering the discretization of geometrical dimensions of commercial bearings, a 
maximum displacement capacity $d_{c}>d_{E d}$ has been chosen, design parameters of the isolation system are reported in Table 3.

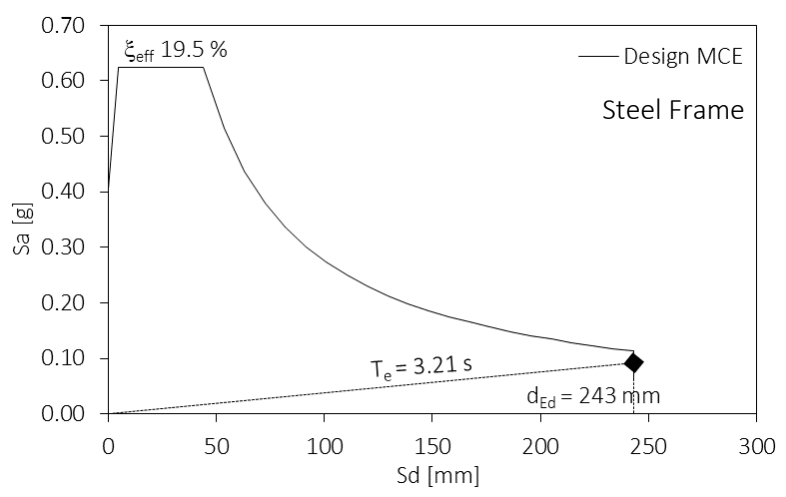

a)

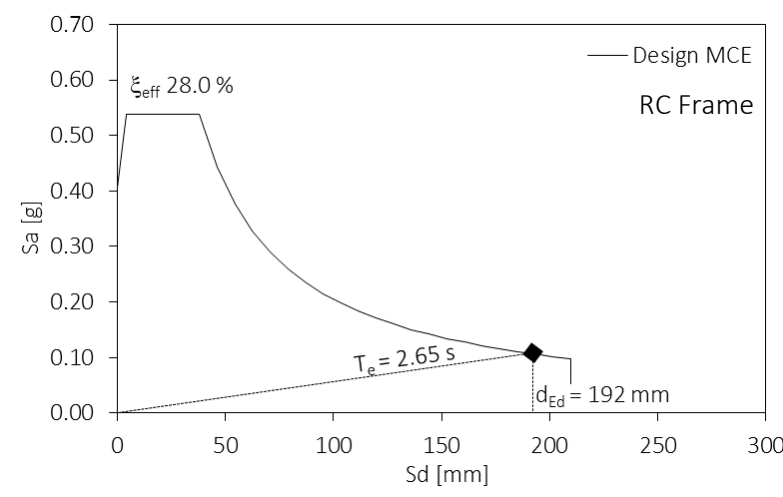

b)

Figure 4: Design of isolation systems for the Steel Frame (a) and the reinforced Concrete Frame (b).

Table 3: - Isolation system design parameters.

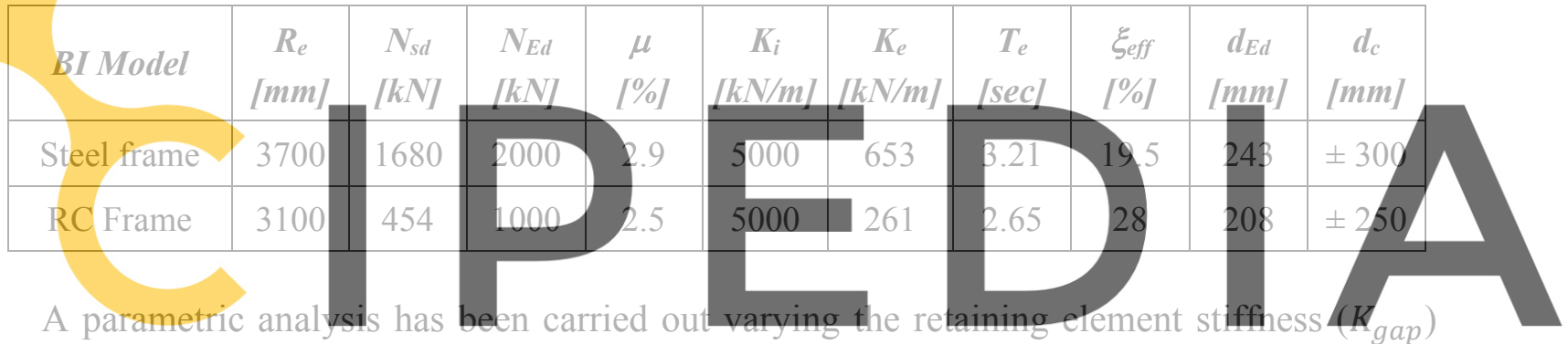

with the following values: infinitely rigid ("Rigid" case), infinitely elastic and equal to $0.25 \%$

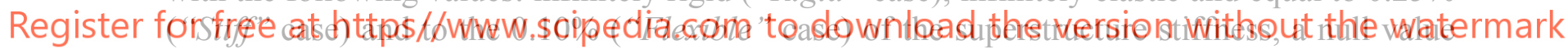
("No_Gap" case). It derives that eight 2-dimensional systems are defined, four for each structure, Figure 5 shows the cases ID and the corresponding gap stiffness.

\begin{tabular}{|c|c|}
\hline Case & $\boldsymbol{K}_{\text {gap }}$ \\
\hline Rigid & Unlimited \\
\hline Stiff & $0.25 \% K_{\text {str }}$ \\
\hline Flexible & $0.10 \% K_{\text {str }}$ \\
\hline No Gap & Null \\
\hline
\end{tabular}

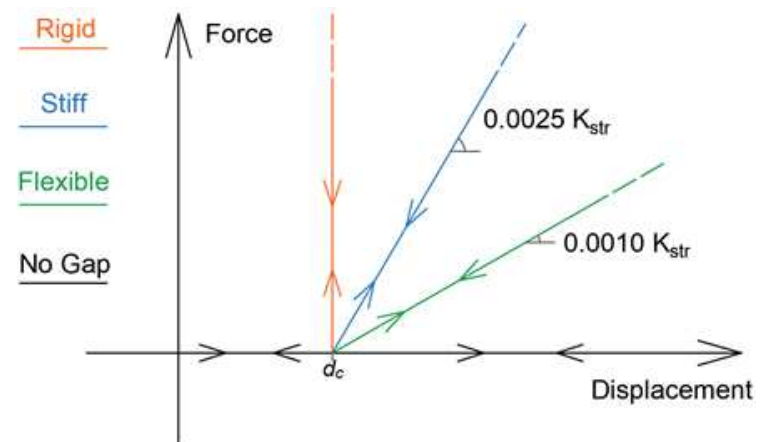

Figure 5: Parametric analysis model characteristics of the restraint elements. 


\section{NONLINEAR ANALYSIS}

\subsection{Non-linear Static analysis}

Pushover analyses for case studies of base isolated and not-isolated frames are presented in Figure 6 for the Steel (a) and the Reinforced Concrete (b) model. A distribution of lateral forces proportional to the floor masses was used in the analyses. The red circled points at the global drift ratios of $1 \%$ and $0.3 \%$ are the yield drift limits. Pushover curves of the Steel isolated building show a reduction of the maximum base-shear force after the elastic branch linked to the major flexural deformability of the base beam layer added.

Pushover curves of models without displacement restraints (black lines) show the basic behaviour. Curves associated to models with displacement restraint show a first branch until the isolators quasi-rigid behaviour (pre-sliding stage), then a second branch primarily accounting for the isolators restoring stiffness, finally, when the maximum base displacement capacity $d_{C}$ is reached, curves show a superstructure response similar the not-isolated one. Models with flexible displacement restraints show a less sloping curve after the $d_{c}$ displacement consistently with the gap stiffness $K_{\text {gap }}$ but tend to show the same maximum base-shear force.

Figure 6 shows that the shape of the pushover curve of isolated structures cannot be approximated by an elastoplastic representation, this means that pushover curves could not always be used in the application of the simplified procedure for spectral shape effect estimation.

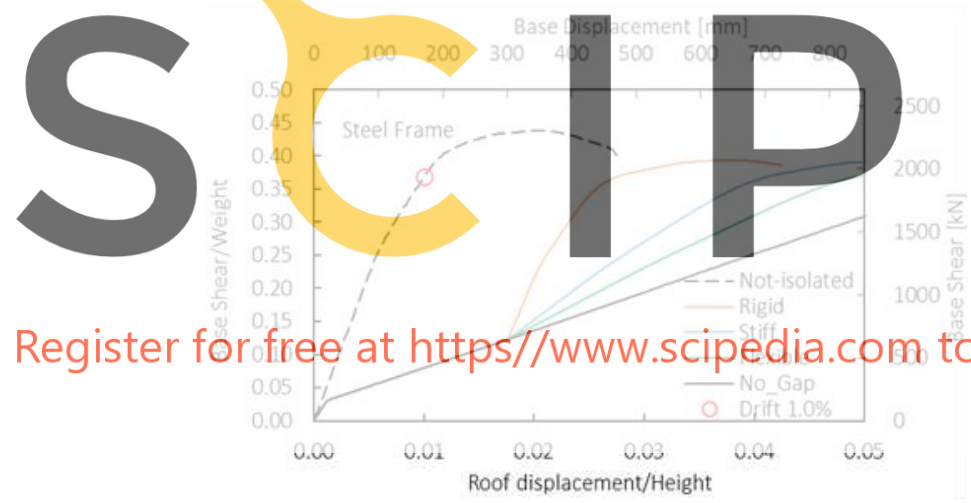

a)

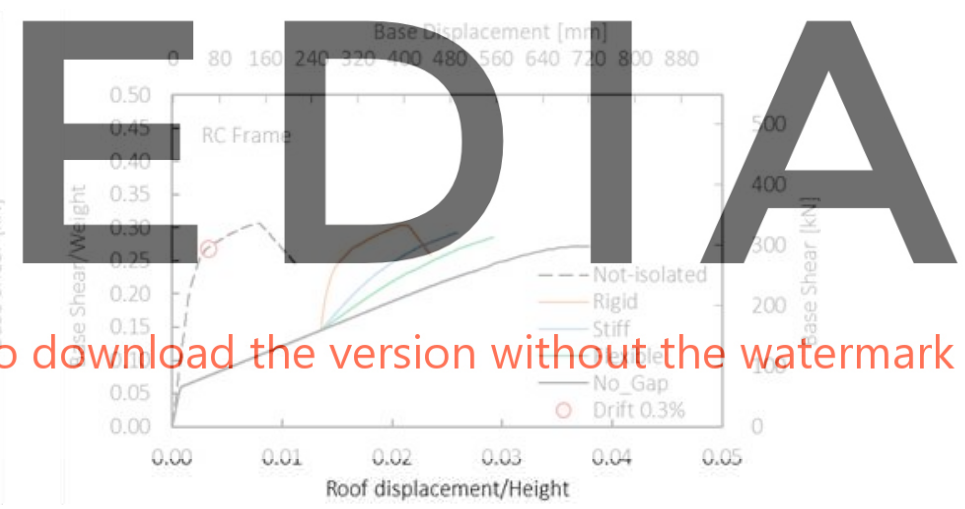

b)

Figure 6: Non-linear static analyses in fixed-base and base-isolated configurations for the Steel Frame (a) and the RC Frame (b).

\subsection{Nonlinear Time History Analysis}

The seismic performance of the case-study buildings has been analyzed using Multi Stripes Analyses (MSA). According to the PEER-like modular approach and the performance-based earthquake engineering (PBEE) approach [22], this work estimates the effects of different displacement restrainers on base isolated structures by considering several natural ground motions with different intensity measures (IM). The record-to-record variability is taken into account using a set of 200 natural seismic records (composed of 20 sets of motions for the 10 selected intensities each, see Table 4) selected from national and international databases based on the ground motion hazard at the site of L'Aquila (Italian site). The Intensity Measure (IM) 
selected to represent the earthquake intensity levels is the spectral acceleration (5\%-damped) corresponding to a reference period (conditioning period) as close as possible to the fundamental period of vibration of $T=3 \mathrm{sec}$ for the base-isolated structures.

Table 4: - Ground motion Return Periods and Conditional Spectral Acceleration.

\begin{tabular}{|c|c|c|c|c|c|c|c|c|c|c|}
\hline Intensity Measure & IM 1 & IM 2 & IM 3 & IM 4 & $\begin{array}{c}\text { IM 5 } \\
\text { DBE }\end{array}$ & $\begin{array}{c}\text { IM 6 } \\
\text { MCE }\end{array}$ & IM 7 & IM 8 & IM 9 & IM 10 \\
\hline Return Period $T_{r}[y]$ & 10 & 50 & 100 & 250 & 500 & 1000 & 2500 & 5000 & 10000 & 100000 \\
\hline$S_{a}(T=3 \mathrm{sec})[g]$ & 0.0002 & 0.011 & 0.031 & 0.062 & 0.110 & 0.177 & 0.271 & 0.384 & 0.576 & 1.053 \\
\hline
\end{tabular}

In this work, the main source for earthquakes time histories was the ITACA record database (http://itaca.mi.ingv.it) [23] while the NGAwest2 database [24] was only used for high spectral accelerations. The Conditional Mean Spectrum (CMS) methodology implies the scaling of all selected records so that they have the same spectral ordinate at the conditioning period for each intensity level. More details about the seismic hazard and record selection for nonlinear dynamic analysis are reported in Iervolino et al (2019) [5].

The Engineering Demand Parameters (EDP) limit conditions are summarized in Table 5. For the superstructure, a global simplified collapse criterion has been chosen, considering the global capacity obtained from pushover analyses as in [25]. Criticism of this approach is known [26]

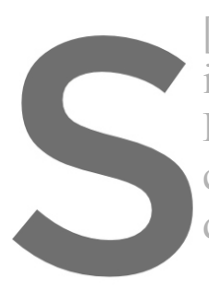
$[27]$, since a capacity
is adopted rather than
Limit is related to the
considered is the devic
displacement capacity
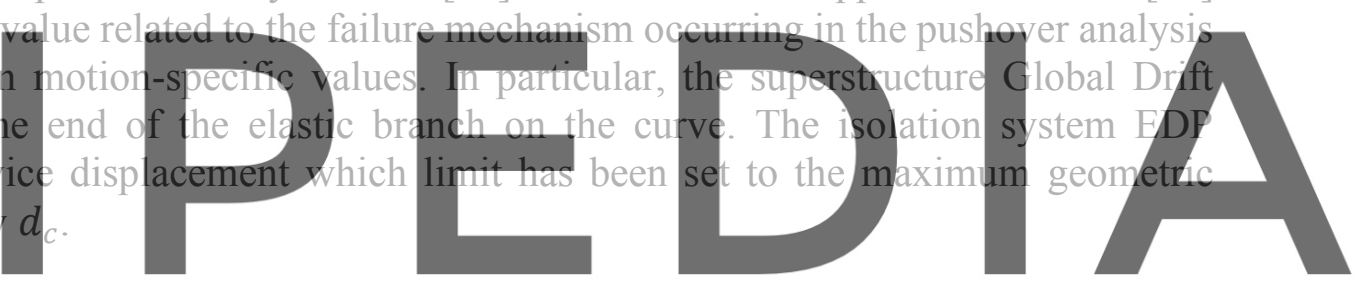

Table 5: - Engineering Demand Parameters reference yalues.

Register for free at https//www.scipedia.com to download the version without the watermark

\begin{tabular}{|c|c|c|}
\hline BI Model & $\begin{array}{c}\text { Superstructure global drift limit } \\
d_{\text {rift }[\%]}[\%]\end{array}$ & $\begin{array}{c}\text { Maximum base displacement capacity } \\
d_{c}[\mathrm{~mm}]\end{array}$ \\
\hline Steel Frame & $1.0 \%$ & $\pm 300 \mathrm{~mm}$ \\
\hline RC Frame & $0.3 \%$ & $\pm 250 \mathrm{~mm}$ \\
\hline
\end{tabular}

As a first result, in Figure 7 models' Base displacements (a) and Drift (b) response vs time are presented for the steel (left) and the RC (right) frames. Figure 7 shows how the "Flexible" cases responses are half-ways between the two borderline cases "Rigid" and "No_Gap". Moreover, results show how a flexible displacement restraint successfully dampens the seismic action resulting in minor superstructural accelerations and displacements preventing impulsive phenomena.

Figure 8 shows fragility curves for the superstructure Global Drift on Steel (a) and Reinforced Concrete (b) models. A fragility function is a mathematical relationship that indicates the probability that a structure or part of it will experience damage at or above a specific seismic intensity. 

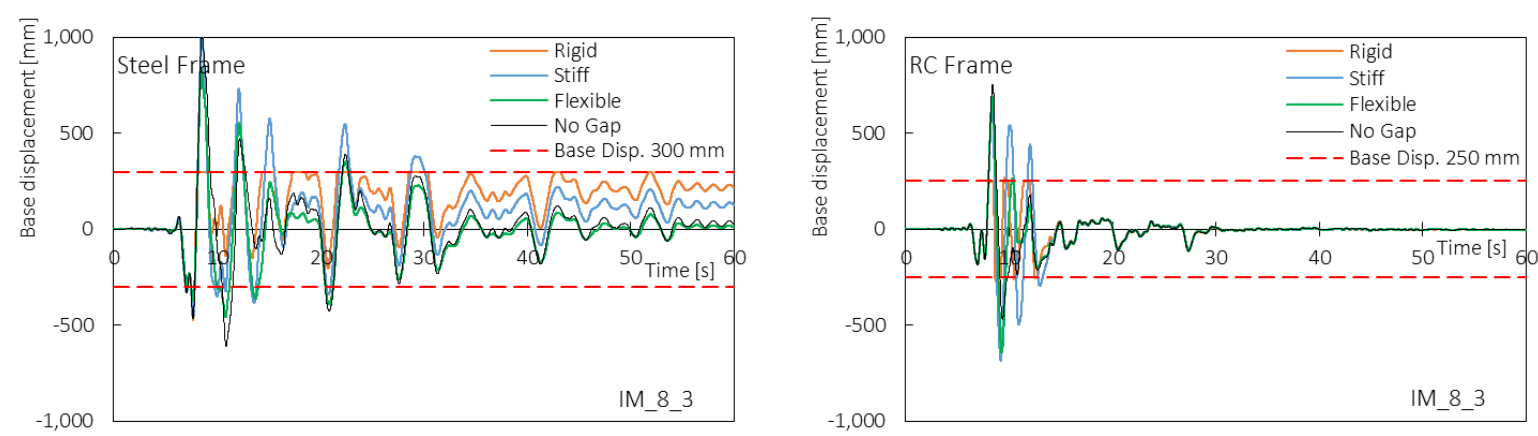

a)
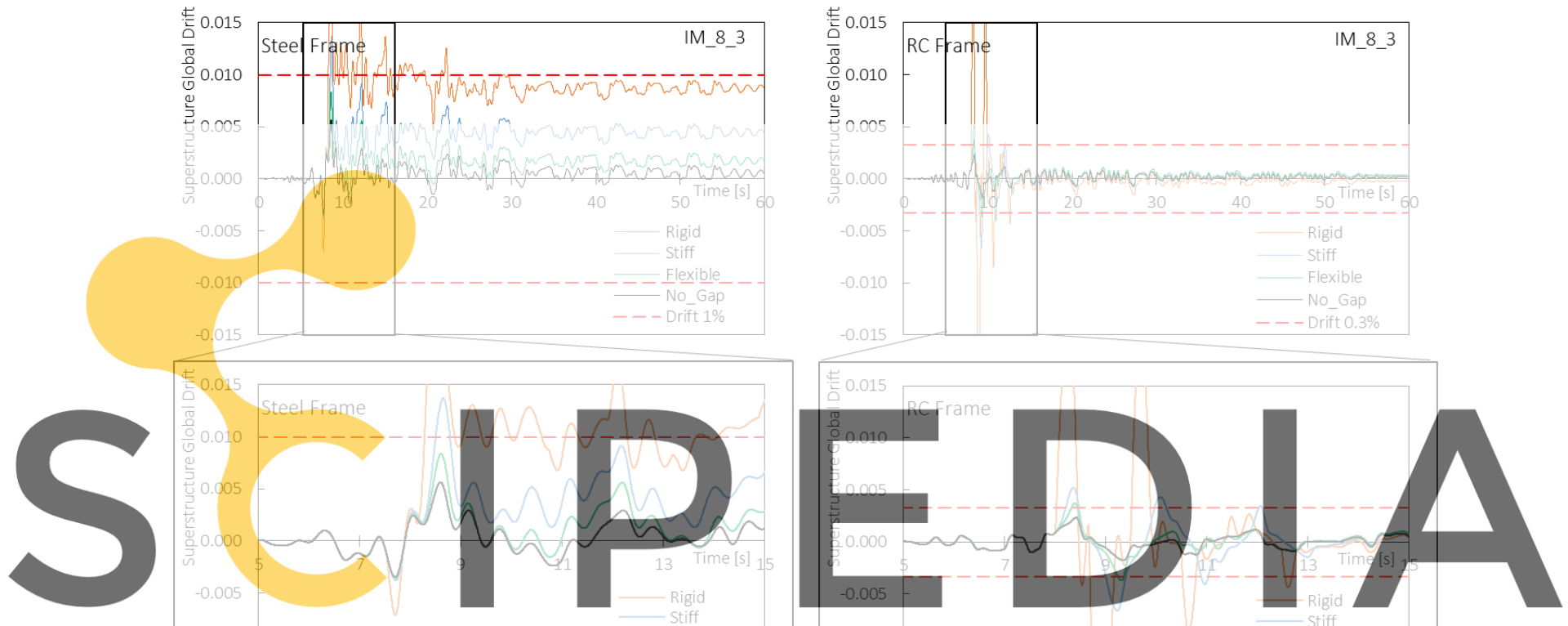

Register for freenat-https//www.scipedia.com to download the version without the watermark

b)

Figure 7: Base displacement (a) and Drift (b) time histories for the Steel Frame (left) and the RC Frame (right).

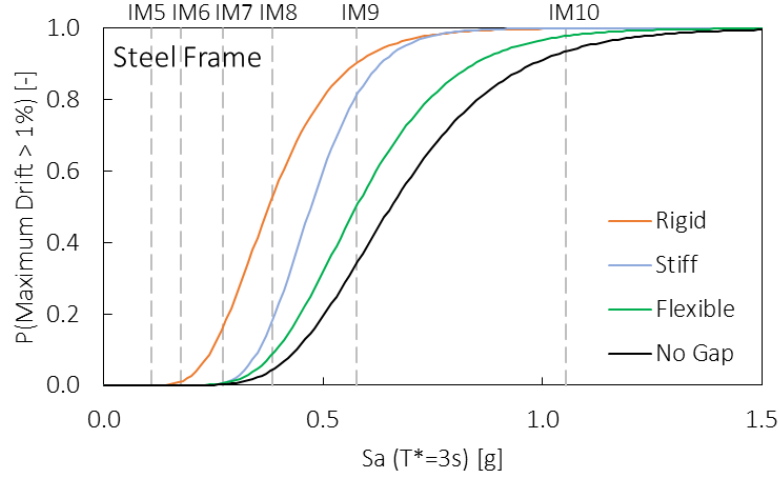

a)

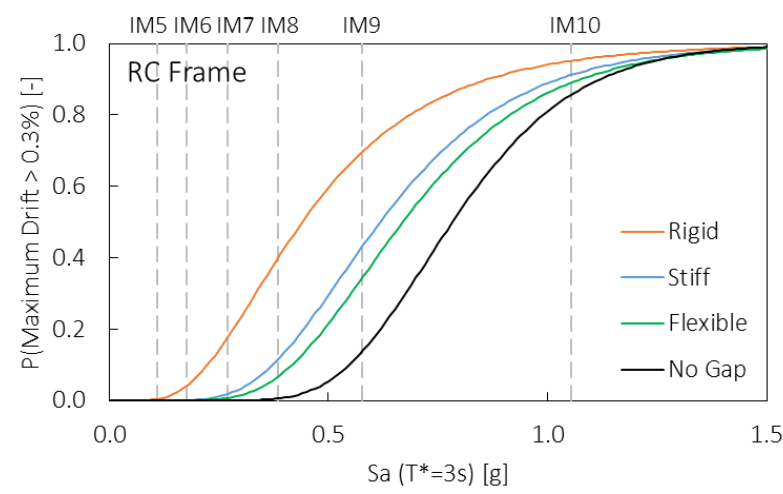

b)

Figure 8: Fragility curves for the Drift limit of (a) $1 \%$ Steel Frame and (b) $0.33 \%$ for the RC Frame. 
Fragility curves are computed to provide a probability distribution of potential damage during earthquakes higher than the MCE (corresponding to IM6).

A lognormal cumulative distribution function Eq. (3) is used to define fragility functions where $\mathrm{P}(\mathrm{C} \mid \mathrm{IM}=\mathrm{x})$ is the probability that a ground motion with intensity $\mathrm{IM}=\mathrm{x}$ will cause the structure to reach the EDP limit value; $\Phi()$ is the standard normal cumulative distribution function (CDF); $\theta$ is the median of the fragility function (the IM level with $50 \%$ probability of exceeding); and $\beta$ is the standard deviation of $\ln (I M)$ (IM dispersion) [28].

$$
\mathrm{P}(\mathrm{C} \mid \mathrm{IM}=\mathrm{x})=\Phi\left(\frac{\ln (x / \theta)}{\beta}\right)
$$

Results show a similar behaviour for the two buildings were, the "Stiff" and "Flexible" cases curves are in the areas in between the "Rigid" and "No_Gap" borderline cases.

\section{CONCLUSIONS}

The presented work focused on the investigation of the effects of displacement restraints on the nonlinear response of base-isolated frame buildings. Developments in terms of modelling have been proposed, in particular, a basic model for the representation of the behaviour of flexible displacement retaining elements has been implemented. The new model has been used in the analysis of two case study frames, a Steel and a Reinforced Concrete one, respectively designed according to the Italian construction code NTC1 8 and the Eurocode 8.

Four basic models "Rigid" one with infin $K_{\text {gap }}=0.10 \% K_{\text {str }}$ "No_Gap".Based on 1 set. Fragility curves have been
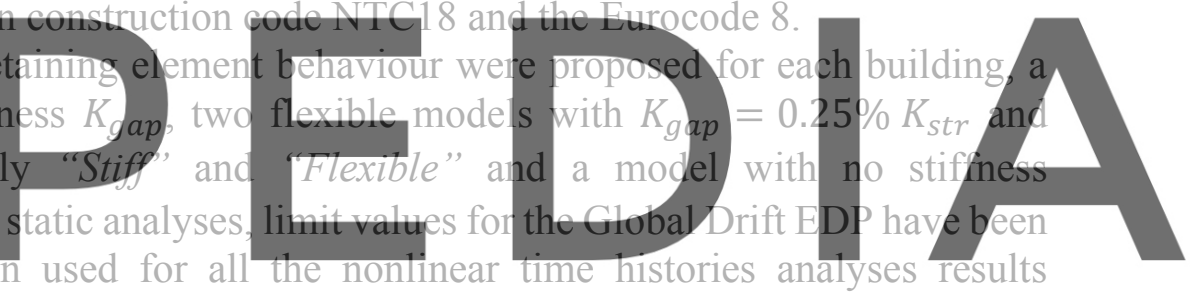

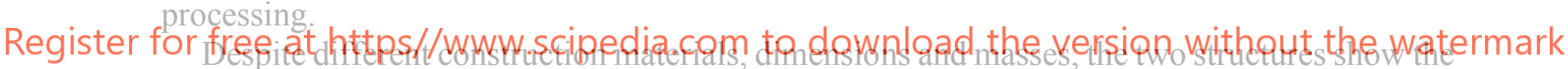
same global tendency. Fragility Curves associated with "Stiff" and "Flexible" cases are halfways between the "Rigid" and the "No_Gap" cases showing how a more flexibie retaining element leads to lower probabilities of exceeding for the same seismic intensity. Moreover, fragility curves and Drift time histories for the "Flexible" case show how a deformable retaining element can improve the superstructural seismic performance preventing impulsive phenomena while keeping the design dimensions of the devices.

Pushover curves also show how the effects of a lower initial stiffness for the Steel superstructure tend to increase the gap between the "Stiff" and "Flexible" fragility curves for high seismic intensities compared to the Reinforced Concrete Frame.

Generally speaking, the preliminary results presented in this study outline that, the retaining elements stiffness can significantly affect the seismic performance of structures for seismic intensities higher than the design one. Further developments are needed to definitively assess the effect of such elements and to identify robust models and even their cyclic behaviour, so new analysis considering more case-study base-isolated buildings are in progress. In conclusion, the present study represents an improvement in the knowledge towards the refinement of the performance assessment of base-isolated buildings with retaining elements. 


\section{ACKNOWLEDGEMENTS}

Authors would like to acknowledge the financial support of RELUIS 2019-2021 project funded by the Italian Civil Protection Department.

\section{REFERENCES}

[1] Kitayama, S., Constantinou, M.C. Effect of displacement restraint on the collapse performance of seismically isolated buildings, BEE, 17(5), 2767-2786 (2019).

[2] Ragni, L., Cardone, D., Conte, N., Dall'Asta, A., Di Cesare, A., Flora, A., Leccese, G., Micozzi, F., Ponzo, F.C. Modelling and Seismic Response Analysis of Italian Code Conforming Base-Isolated Buildings, JEE, Vol. 22(2), pp. 198-230, (2018).

[3] Ponzo, F.C., Di Cesare, A., Leccese, G., Nigro, D. Shake table testing on restoring capability of double concave friction pendulum seismic isolation systems, EESD, Vol 46(14), pp. 2337-2353, (2017).

[4] Di Cesare, A., Ponzo, F.C., Telesca, A., Nigro, D., Castellano, M.G., Infanti, S., Fichera, S., Biondi, B. Modelling of the over stroke displacement of curved surface sliders using OpenSEES, Proc. of First Eurasian Conference on OpenSees, Hong Kong, 20-21 (2019).

[5] Iervolino, I., Spillatura, A, Bazzurro, P. Seismic Reliability of Code-Conforming Italian Buildings, JEE, Vol. 22(2), pp. 5-27, (2019).

[6] Sorace, S., Terenzi, G. Innovative Structural Solutions for Prefab Reinforced Concrete Hall-Type Buildings. The Open Construction and Building Technology Journal, 13(1). (2019).

[7] Terenzi, G., Sorace, S., Spinelli, P., Rossi, E. Seismic protection of a historical R/C elevated water tank by different base isolation systems. Ingegneria Sismica, 36(2), 137-158. (2019).

[8] Brito, M. B., Ishibashi, H., Akiyama, M. Shaking table tests of a reinforced concrete bridge pier with a low-cost sliding pendulum system. EESD, 48(3), 366-386. (2019).

[9] Masroor, A., G. Mosqueda. Impact model for simulation of base isolated buildings impacting flexible moat walls. EESD 42.3 (2013): 357-376.

[10] Bao, Y., Becker, T. C., Sone, T., \& Hamaguchi, H. Experimental study of the effect of restraining rim design on the extreme behavior of pendulum sliding bearings. EESD, 47(4), 906-924. (2018).

[11] De Domenico, D., Gandelli, E., Quaglini, V. Adaptive isolation system combining lowfriction sliding pendulum bearings and SMA-based gap dampers. ES, 212, 110536. (2020).

[12] De Domenico, D., Gandelli, E., Quaglini, V. Effective base isolation combining lowfriction curved surface sliders and hysteretic gap dampers. SDEE, 130, 105989. (2020).

[13] Mckenna, F., Fenves, GL., Scott, MH., Jeremic, B. Open system for earthquake engineering simulation (OpenSEES). Berkeley (CA): PEER Center, University of California. (2000).

[14] Quaglini, V., Bocciarelli, M., Gandelli, E., Dubini, P. Numerical assessment of frictional heating in sliding bearings for seismic isolation. JEE, vol. 18, p. 1198-1216. (2014).

[15] Kitayama, S., Constantinou, M.C. Effect of displacement restraint on the collapse performance of seismically isolated buildings. BEE, 1-20, 2019.

[16] Ponzo, F.C., Di Cesare, A., Telesca, A., Nigro, D., Castellano, M.G., Infanti S. Influence of DCCSS Bearings Over-Stroke and breakaway on the seismic response of isolated 
buildings. Proc. of 17th WCEE, Sendai, Japan. (2020).

[17] Di Cesare, A., Ponzo, F.C., Telesca, A., Improving the earthquake resilience of isolated buildings with double concave curved surface sliders, ES, 111498, ISSN 0141-0296, https://doi.org/10.1016/j.engstruct.2020.111498. (2020).

[18] NTC-18, Italian Technical Code for constructions (in Italian). Ministry of Infrastructures, Italy 17/01/2018. (2018).

[19] Mazza F., Vulcano A. Effects of near-fault ground motions on the nonlinear dynamic response of base-isolated $R C$ framed buildings. EESD 41.2 (2012): 211-232.

[20] Eurocode 8. Design of structures for earthquake resistance-part 1: general rules, seismic actions and rules for buildings. C.E.N., European Committee for Standardization, December (2003).

[21] Lignos, D. G., Krawinkler, H. Deterioration modeling of steel components in support of collapse prediction of steel moment frames under earthquake loading. JSE, 137.11: 12911302. (2011).

[22] Porter, K.A. An overview of PEER's performance-based earthquake engineering methodology. In Proceedings of ninth international conference on applications of statistics and probability in civil engineering. (2003).

[23] Luzi, L., et al. ITACA (ITalian ACcelerometric Archive): a web portal for the dissemination of Italian strong-motion data. Seismological Research Letters, 79.5: 716722. (2008).

[24] Ancheta, T.D., et al. Peer NGA-West2 database. http://ngawest2.berkeley.edu/ (2013).

[25] Ragni, L., Cardone, D., Conte, N., Dall'Asta, A., Di Cesare, A., Flora, A., ... \& Ponzo, F. RINTC-e project: the seismic risk of existing Italian RC buildings retrofitted with seismic isolation. In COMPDYN 2019-7th ECCOMAS Thematic Conference on Computational Methods in SDEE. (2019).

[26] Villaverde, R. Methods to assess the seismic collapse capacity of building structures: State of the art. JSE, 133(1), 57-66. (2007).

[27] Goulet, C. A., Haselton, C. B., Mitrani- Reiser, J., Beck, J. L., Deierlein, G. G., Porter, K. A., Stewart, J. P. Evaluation of the seismic performance of a code conforming reinforcedconcrete frame building from seismic hazard to collapse safety and economic losses. EESD, 36(13), 1973-1997. (2007).

[28] Baker, J.W. Efficient analytical fragility function fitting using dynamic structural analysis. Earthquake Spectra, 31.1: 579-599. (2015). 